\title{
Simulation and Verification of Jiangsu Sea Area Wind Field Model and Its Storm Surge
}

\author{
D. A. Wu and S. L. Zhao
}

\begin{abstract}
The No.1109 Typhoon wind field has been achieved through calculation with the model of Fujita air pressure and Miyazaki masae wind field based on the measured data, and having compared its data with the actual measured win speed from field station of Datang Power plant and Sun-island in Jiangsu Coastal region and by this way verified its precision of this kind of wind field model. Then the data obtained from ECMWF and calculated from Miyazaki masae wind model will be taken as the input wind field, so as to carry out numerical simulation on the process of storm surge elevation resulted from the No.1109 passing typhoon; The comparative analysis of storm surge has been made between the sea water level calculated from the two sets of simulated input field and the actual measured data from Xiangshui Station and Datang Power plant, finally the effectiveness of simulated storm surge elevation process by the wind field calculation model has been verified. The results of this study are of engineering application value for wind energy development and utilization in Jiangsu coastal areas.
\end{abstract}

Index Terms-Fujita air pressure field, Miyazaki masae wind field, Storm surge, Jiangsu coastal areas.

\section{INTRODUCTION}

The numerical simulation of storm surge is carried out on the basis of numerical simulation forecasting. The selection of the pressure field and typhoon field is very important for the accuracy and timeliness of the simulation results. The accuracy of the storm surge numerical model prediction mainly depends on the selection accuracy of the storm surge model and the pressure field. At present typhoon pressure field and wind field model also has many types [1]-[3], the method of verifying whether the typhoon is accurate or not can be compared indirectly by verifying the storm surge. The pressure field and wind field are given by a parameterized model, and the pressure field and wind field are calculated by giving the appropriate parameters such as typhoon center pressure, maximum wind speed radius, etc. [4]-[6].

Manuscript received November 17, 2016; revised May 17, 2016. This work was supported in part the National Nature Science Foundation Fund of China Project (51279055).

D. A. $\mathrm{Wu}$ is with the College of Harbor, Coastal and Offshore Engineering, Hohai University, Nanjing, 210098, China (e-mail: wudeian@163.com)

S. L. Zhao is with Zhejiang Electric Power Design Institute, China Energy Engineering Group Co., Ltd., HZ, 310012, China (e-mail: zhaoshuln@163.com).

\section{MODEL OF TYPHOON WIND FIELD AND PRESSURE FIELD}

\section{A. Selection of Wind Field}

Wind field is a key factor in the process of numerical simulation of storm surge. During the process of storm surge numerical simulation, it is necessary to give the wind stress value of every grid cell in the calculation area. Miyazaki masae wind field model [3] was chosen as the numerical method of wind field calculation. Miyazaki masae wind field model consists of two parts: one is the wind speed related to the moving speed of the typhoon center, and the other is the symmetrical gradient wind speed related to the typhoon pressure gradient.

The calculation formula of wind speed component in $\mathrm{x}, \mathrm{y}$ direction can be expressed as follows:

$$
\begin{gathered}
W_{x}=C_{1} V_{0 x} \exp \left(-\frac{r \pi}{5 \times 10^{5}}\right)- \\
C_{2} \frac{f}{2}\left(\sqrt{1+\frac{4 \Delta P}{\rho_{a} f^{2} r_{0}^{2}} Z^{3}}-1\right) \times \\
{\left[\left(x-x_{0}\right) \sin \beta+\left(y-y_{0}\right) \cos \beta\right]} \\
W_{y}=C_{1} V_{0 y} \exp \left(-\frac{r \pi}{5 \times 10^{5}}\right)+ \\
C_{2} \frac{f}{2}\left(\sqrt{1+\frac{4 \Delta P}{\rho_{a} f^{2} r_{0}^{2}} Z^{3}-1}\right) \times \\
{\left[\left(x-x_{0}\right) \cos \beta-\left(y-y_{0}\right) \sin \beta\right]}
\end{gathered}
$$

In which: $C_{1}$ is the field wind coefficient, the range is (4/7-6/7); $C_{2}$ is gradient wind coefficient, the value is 0.6 for the weak typhoon, the range is $(0.7-0.8)$ for the strong typhoon, the range also can be determined by the measured value; $f=2 \omega \sin \varphi$ is geotropic parameters, $\omega$ is angular velocity of ground, $\varphi$ is the geographic latitude of the waters ; $\beta$ is the gradient wind and sea surface wind correction, here $\beta$ is $30^{\circ} ; V_{0 x}$ and $V_{0 y}$ are the components of the direction and direction of the moving speed of the typhoon center; $\rho_{a}$ is the air density; $Z=\left(1+\left(r / r_{0}\right)^{2}\right)^{0.5}$; Among them, $V_{0 x}$ $V_{0 y}, P_{0}$ at different time can be checked by liner interpolation 
of the data in Typhoon Yearbook.

After the wind field is determined, the wind stress at any point on the sea surface is:

$$
\left(\tau_{0 x}, \tau_{0 y}\right)=\rho_{a} C_{w} \sqrt{W_{x}^{2}+W_{y}^{2}}\left(W_{x}, W_{y}\right)
$$

where $C_{w}=0.001\left(1+0.07 \sqrt{W_{x}^{2}+W_{y}^{2}}\right)$ is the coefficient of drag force on the surface; $\rho_{a}$ is air density; $W_{x}, W_{y}$ are the wind speed in the $\mathrm{x}$ and $\mathrm{y}$ direction(the wind speed at the height of $10 \mathrm{~m}$ above water ).

\section{B. Selection of Pressure Field Mode}

Fujita air pressure field model has been selected as below [7]:

$$
P_{a}=P_{\infty}-\Delta P /\left(1+\left(r / r_{0}\right)^{2}\right)^{0.5}
$$

in which: $P_{\infty}$ is the air pressure of typhoon periphery, the standard atmospheric pressure here is $1.01325 \times 10^{5} \mathrm{~Pa}$; $\Delta P=P_{\infty}-P_{0}, \quad P_{0}$ is the air pressure of the typhoon center, $r$ is the distance between any point in the region and the typhoon center; $r_{0}$ is the typhoon parameter.

Usually for a typhoon, $r_{0}$ varies with the movement and pressure field of typhoon center.The selection of $r_{0}$ has a direct influence on the wind speed profile in the wind field model, as well as the authenticity of the wind field. The maximum wind speed radius plays an important role in the wind field simulation process. Usually, the maximum wind speed radius is calculated from the measured atmospheric pressure near the center of the typhoon, or measure the magnitude of the six gale as the maximum wind speed radius from the weather map.

\section{CONSTRUCTION AND VERIFICATION}

\section{A. Introduction of Typhoon}

In this paper, the tropical storm "Muifa" (No. 1109) has been selected in 2011 to simulate typhoon wind field, and use the above typhoon wind field model to construct the typhoon wind field as a storm surge model. The simulation results have been compared with the measured data and the response process of water level and flow has been analyzed and studied. "Muifa" generated at 14:00 on July 28 in the northwest Pacific Ocean surface, then upgraded to super typhoon twice, and weakened into a typhoon at 6:00 on August 6 .At 11 o'clock on the August 6, Zhoushan City, Zhejiang Province, the center of the typhoon was located about $425 \mathrm{~km}$ southeast of the East China Sea, the maximum wind near the center is level 14. The part path of 'Muifa' is as shown in Fig. 1.

\section{B. Construction of Typhoon Wind Field}

The basic step of constructing wind field is to construct the wind speed profile of typhoon at different times by using typhoon center pressure and maximum wind speed radius. The sea surface wind field at $10 \mathrm{~m}$ was obtained by combining with the position and moving speed of the typhoon center and constructing at different times of typhoon wind field. Here comparing the calculated wind field with the downloaded wind field in Fig. 2 and Fig. 3.

It can be seen that the wind field constructed by the typhoon wind field model in this paper reflects the basic structure of the typhoon.

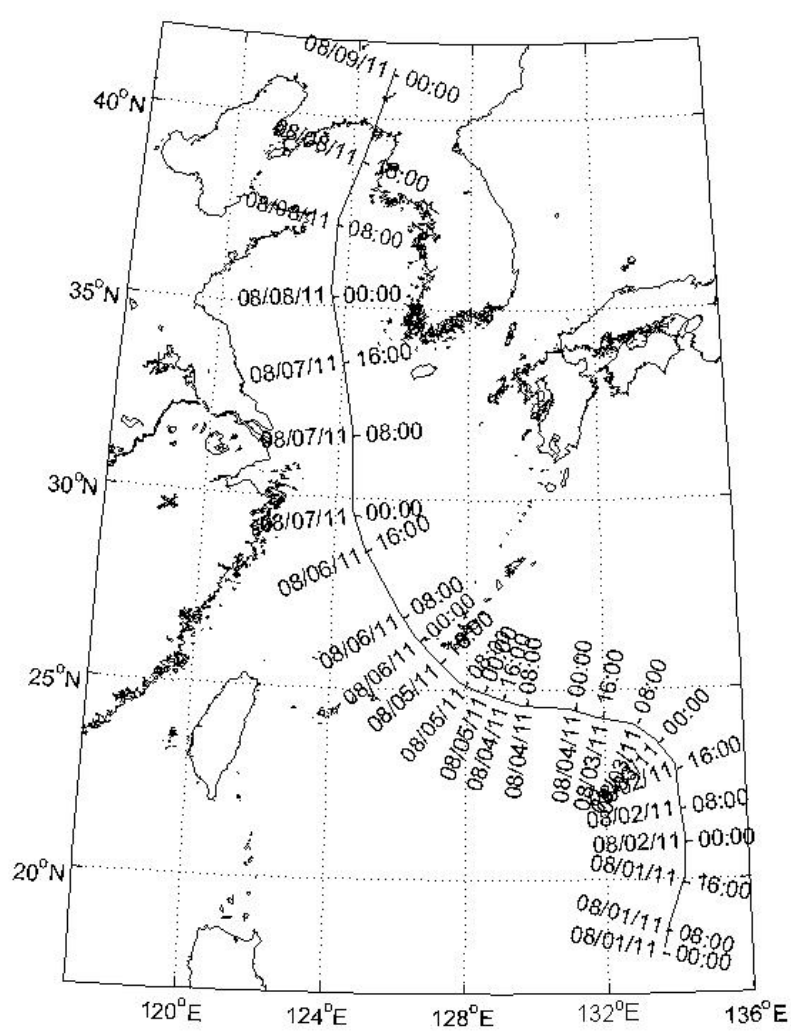

Fig. 1. The path of the typhoon 'Muifa".

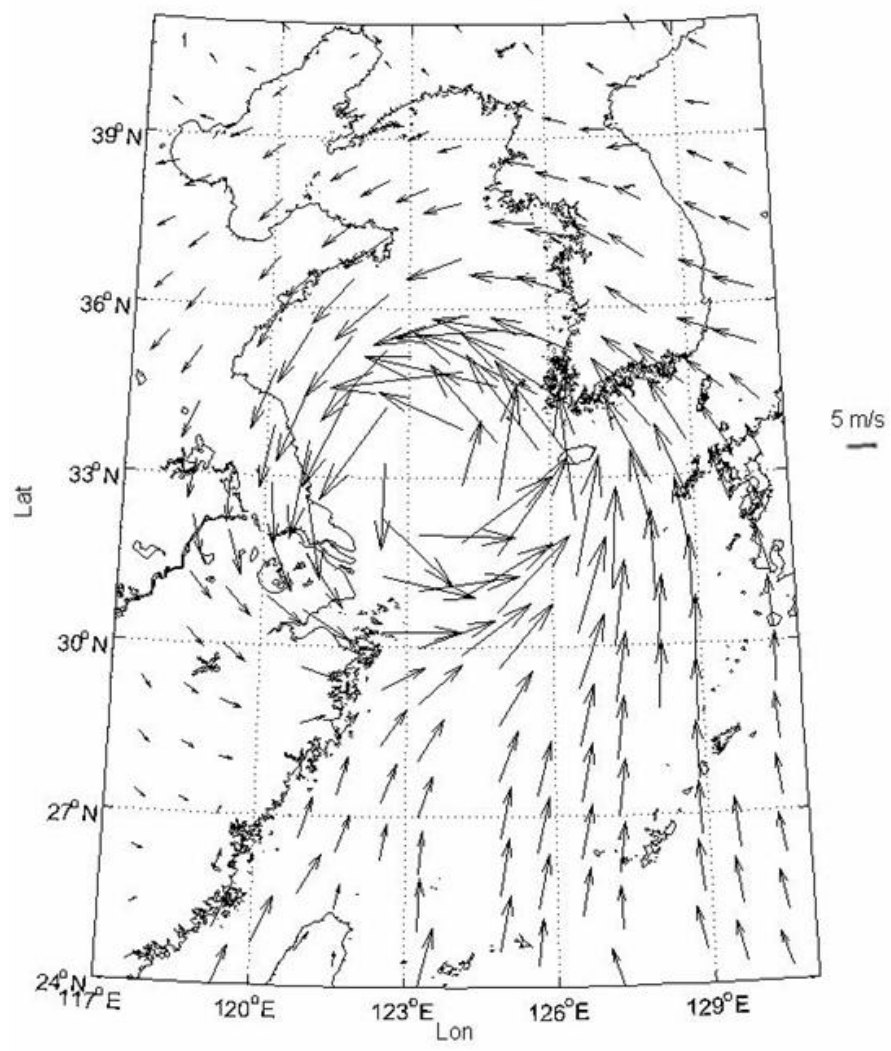

Fig. 2. ECMWF wind field (14:00, Aug. 7th ). 


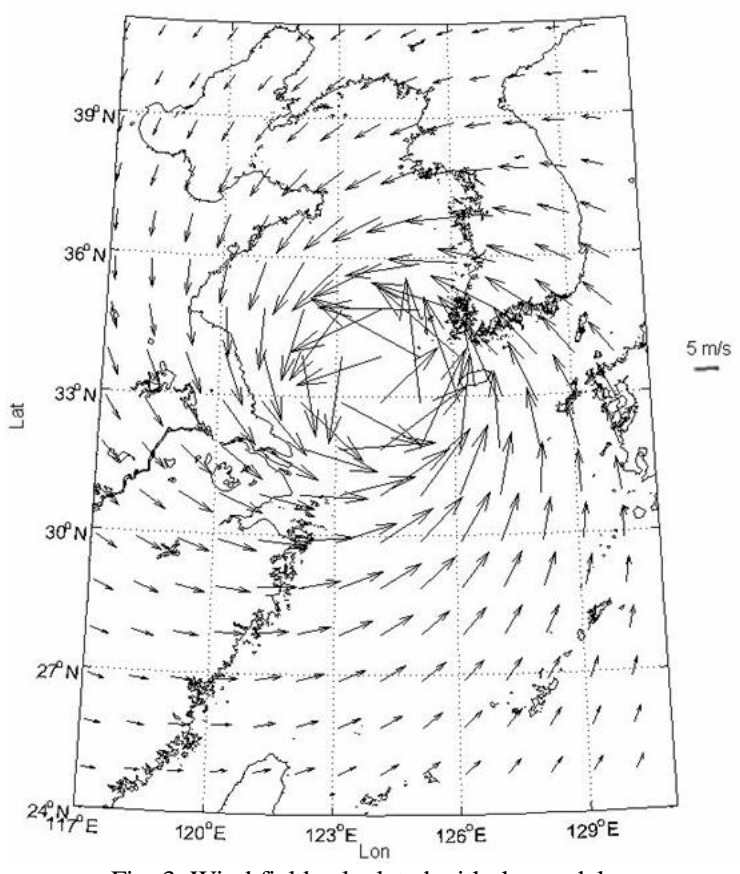

Fig. 3. Wind field calculated with the model.

The wind speed measured at Datang power plant $\left(121.71382^{\circ} \mathrm{E}, 32.0359309^{\circ} \mathrm{N}\right)$ and Sun Island Station $\left(121.36222{ }^{\circ} \mathrm{E}, 32.5503930{ }^{\circ} \mathrm{N}\right)$ on 6 th to 9 th August 2011 is compared with the wind speed calculated by wind field model in this paper. It can be seen in Fig. 4 and Fig. 5 that the wind field model has good accuracy.

\section{Verification and Analysis of Storm Surge}

The storm surge model [8] has been established by using the SELFE model [9]. The constructed typhoon wind field is taken as a surface forcing input model, and the storm surge model is driven together with open boundary astronomical tidal forces to simulate the typhoon-induced storm surge process. The calculating time is from 0:00 on July 15th, 2011 to 23:00 on August 31st, 2011. The time of forced wind is from 0:00 on August 1, 2011 to 0:00 on August 9, 2011, the forced time interval is one hour, and the calculated results of sea water level and flow velocity has been output per one hour.

In order to further verify the storm surge elevation result calculated with the SELFE model under the forcing of the model wind field, here to compare the storm tide simulated by the wind field based on the observations of the water level in the two stations of Xiangshui Station and Datang Wind Power plant from 0:00 on August 6, 2011 to 0:00 on August 9, 2011, and the wind field calculated from the wind farm model in this paper and the wind field downloaded from ECMWF. The time interval of measuring the water level is one hour, and the comparison result is shown in Fig. 6 and Fig. 7.

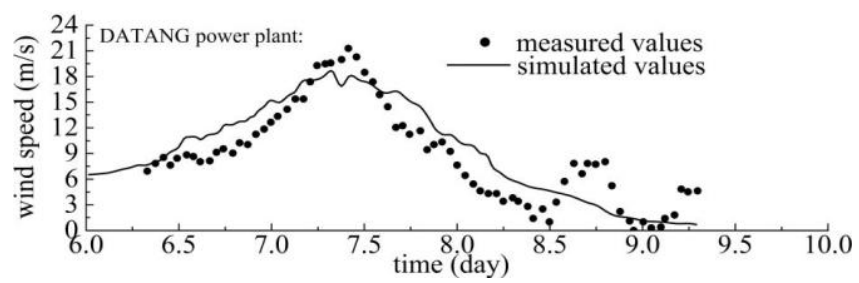

Fig. 4. Wind speed process line in Datang Power plant.

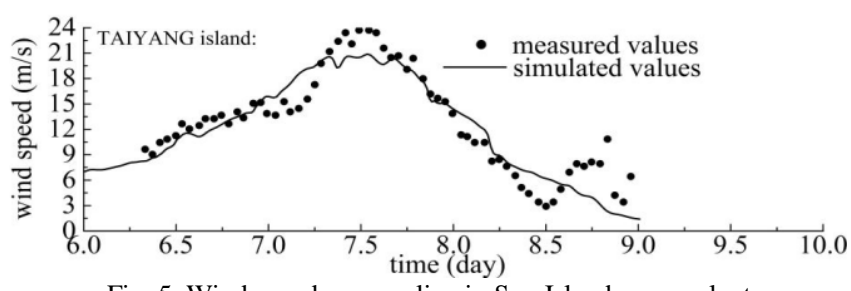

Fig. 5. Wind speed process line in Sun Island power plant.

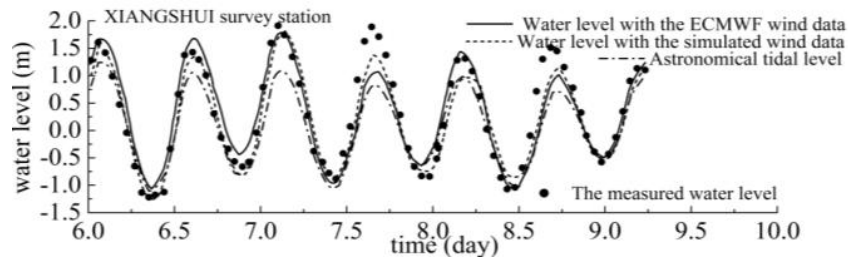

Fig. 6. Water level process line in Xiangshui Station.

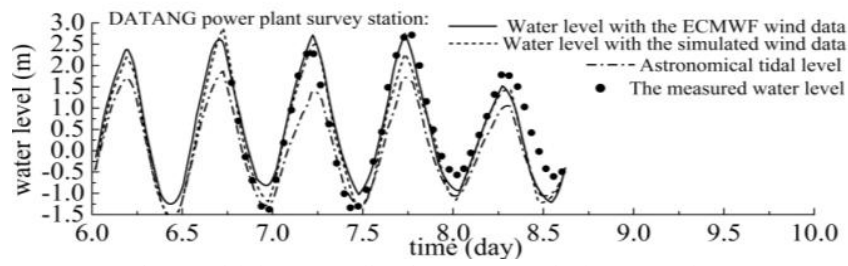

Fig. 7. Tidal process line in Datang Wind Power Plant.
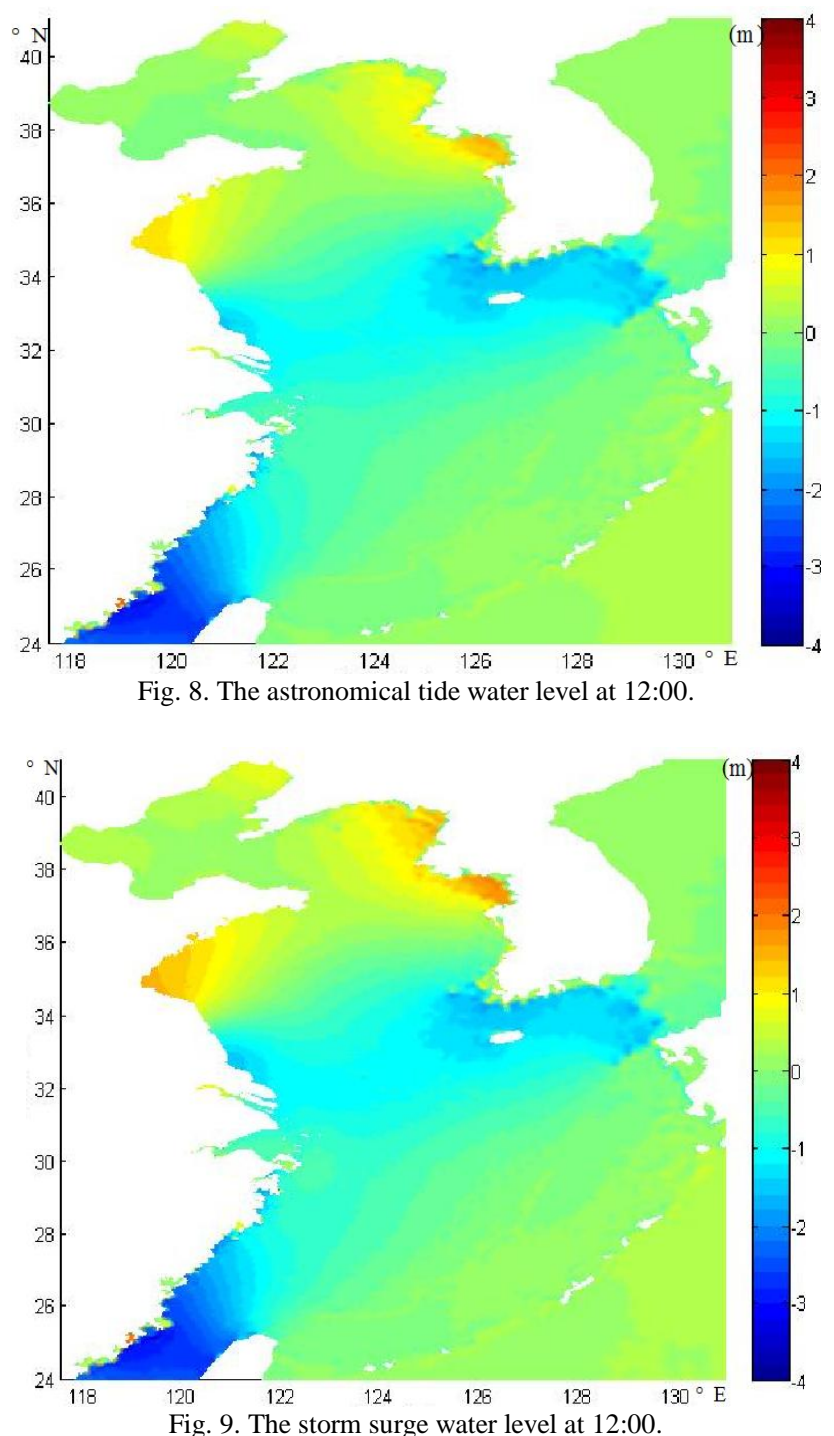

Fig. 9. The storm surge water level at 12:00. 


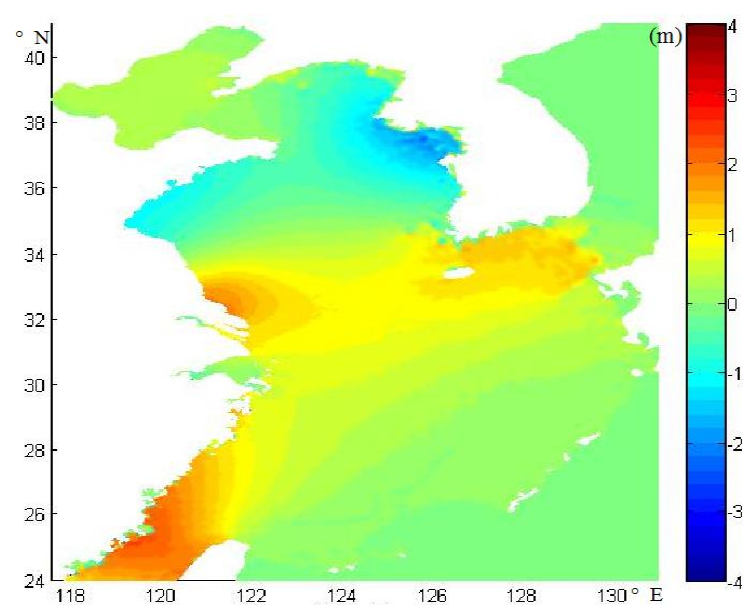

Fig. 10. The astronomical tide water level at 18:00

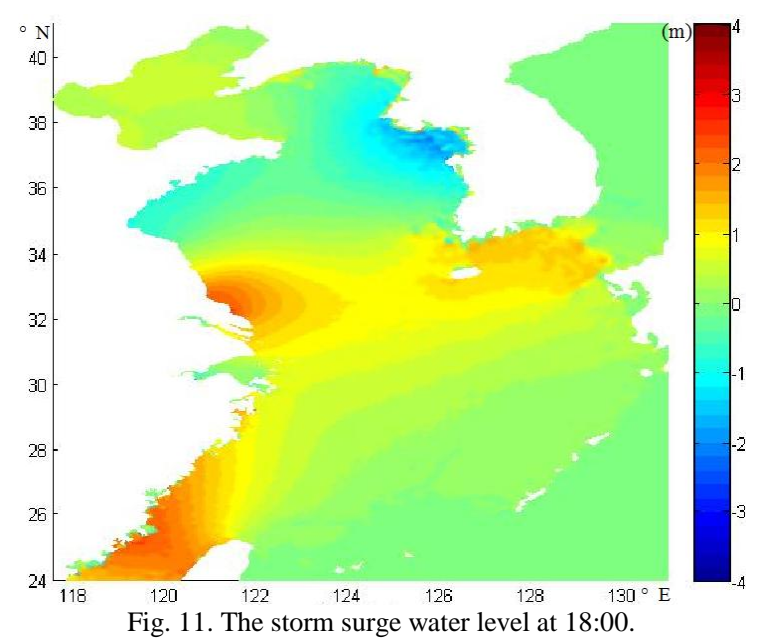

It can be seen that the sea water level simulated by these two sets of wind field data can accurately reflect the actual measured water level during the storm surge. It also can be seen that during the typhoon transit, the water level in the station fluctuates up and down, and the period coincides with the astronomical tidal cycle. The typhoon does not affect the original astronomical tidal circle of the water level shock, but affects the amplitude.

Fig. 8 shows the water level distribution at the neap tide stand (12:00 on August 7st, 2011) of the radial sand ridge in Jiangsu Coast, which was simulated by the SELFE mode only with the astronomical tide boundary input. Fig. 9 shows the storm surge water level distribution at the same time, which was simulated by the above mentioned storm surge model with the model of Fujita air pressure and Miyazaki masae wind field input. In the same way, Fig. 10 shows the water level distribution at the neap tide stand (18:00 on August 7st, 2011) of the radial sand ridge in Jiangsu Coast, which was simulated by the SELFE mode only with the astronomical tide boundary input. Fig. 11 shows the storm surge water level distribution at the same time, which was simulated by the above mentioned storm surge model with the model of Fujita air pressure and Miyazaki masae wind field input.

Therefore we can conclude that, at the neap tide stand of radial sand ridge in Jiangsu Coast, both the astronomical tide water level and the storm surge water level in most areas is almost the same. There was significant storm surge elevation in the Haizhou bay waters. The storm surge water level was apparently higher than the astronomical tide water level. The storm surge water was more obvious there, which was In accordance with the above results shown in Fig. 6 and Fig. 7.

Fig. 12, 13, and 14 show separately the current velocity field of the astronomical tide, the current velocity field of the storm surge velocity, and the wind driven current field of the East China Sea at the flood tide torrent moment during the neap tide in radial sand ridges of Jiangsu Province ( at 16:00 on August 7, 2011).

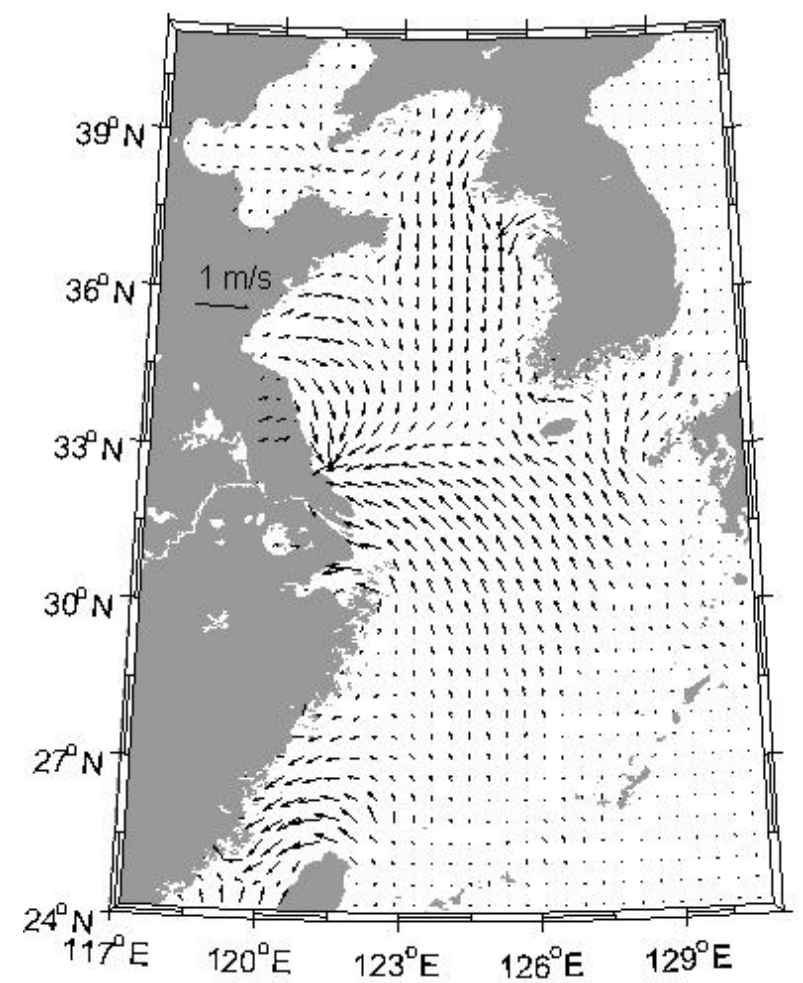

Fig. 12. The astronomical tide current velocity field (at 16:00 on August 7, 2011).

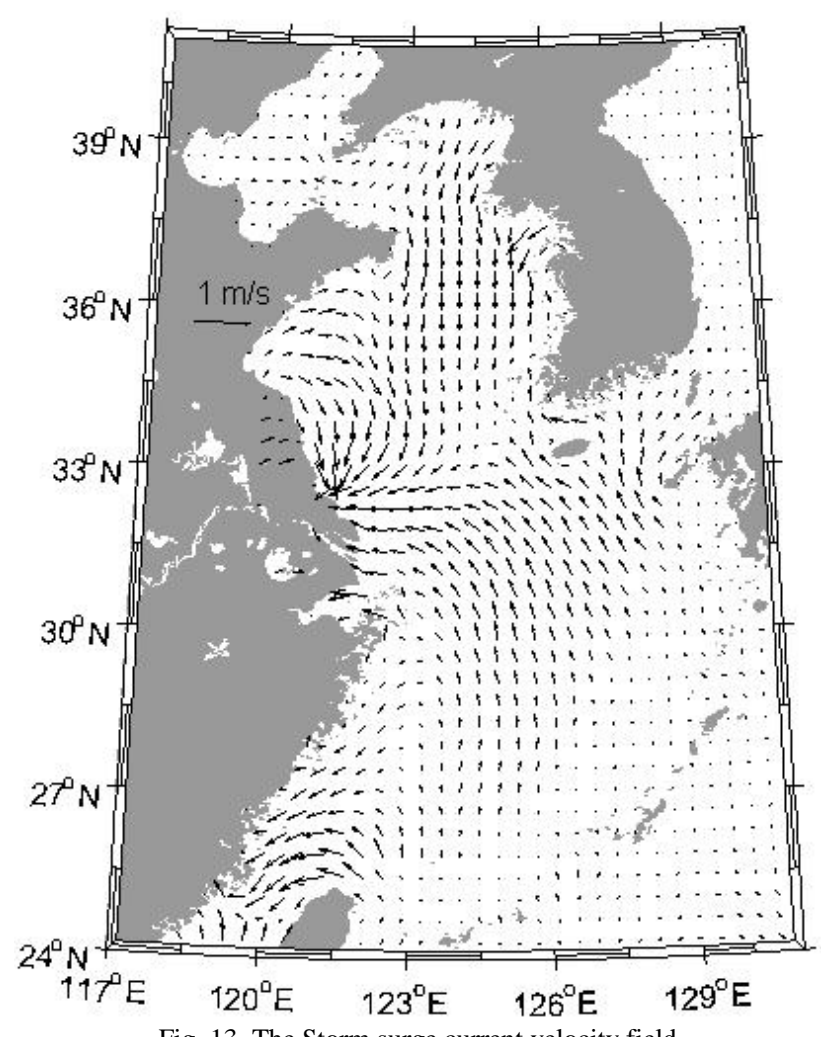

Fig. 13. The Storm surge current velocity field (at 16:00 on August 7, 2011). 


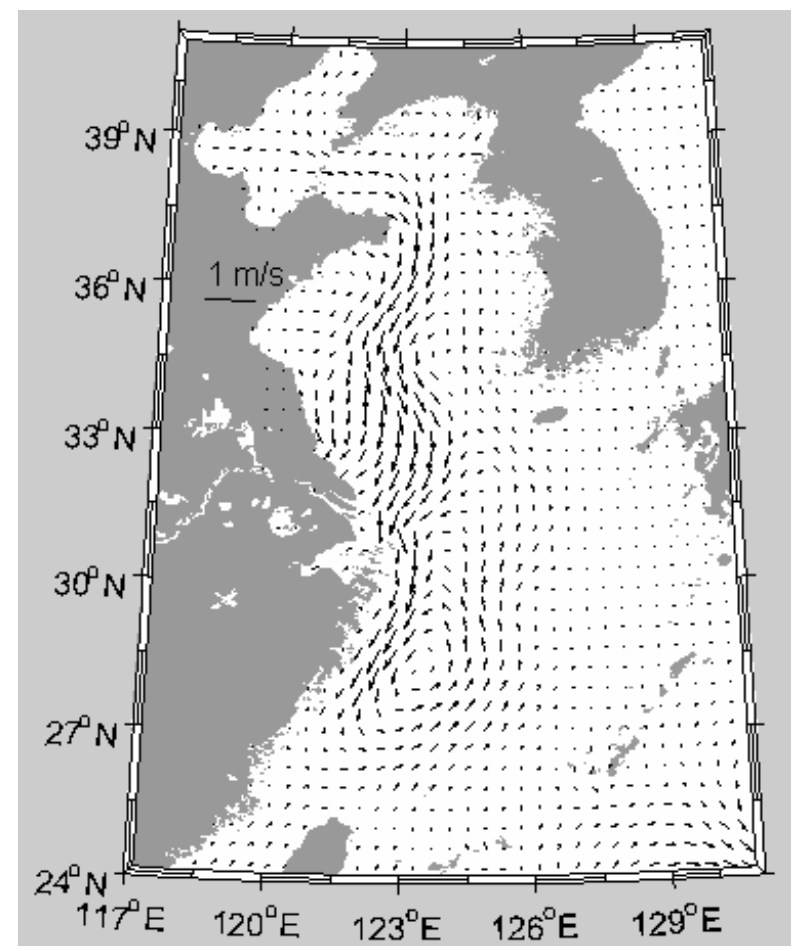

Fig. 14. The wind driven current velocity field (at 16:00 on August 7,2011).

Fig. 15, 16, and 17 show separately the astronomical tide current velocity field, storm surge current velocity field, and wind driven current field of the East China Sea at the ebb tide torrent moment (at 22:00 on August 7, 2011) during the neap tide in radial sand ridge of Jiangsu Province.

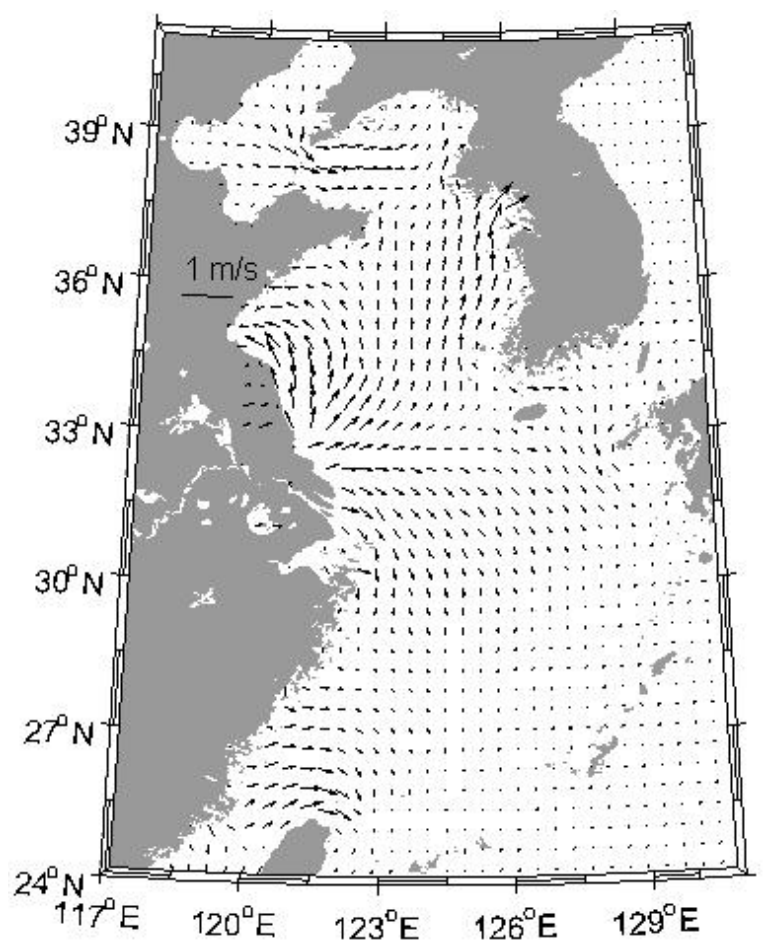

Fig. 15. The astronomical tide current velocity field (at 22:00 on August 7, 2011).

It can been seen that the current field of the whole East China Sea simulated by the model are in good agreement with the measured current field. The storm surge current velocity during the flood tide in radial sand ridges of Jiangsu Province gather together towards Jianggang, and it diverges during the ebb tide, also the typhoon does not change the divergence of the tidal current in radial sand ridges. The typhoon "Muifa" moved and developed roughly along the $124^{\circ} \mathrm{E}$ line from the south to the north in the Yellow Sea area. The strong southward wind driven current appeared in the west side of the typhoon center migration path and the weak northward wind driven current appeared in the east side of the typhoon path. Among them, the wind driven current at the flood tide torrent moment was stronger than those at the ebb tide torrent moment, and the noticeably convergent of the wind driven current velocity appeared at the flood tide torrent moment.

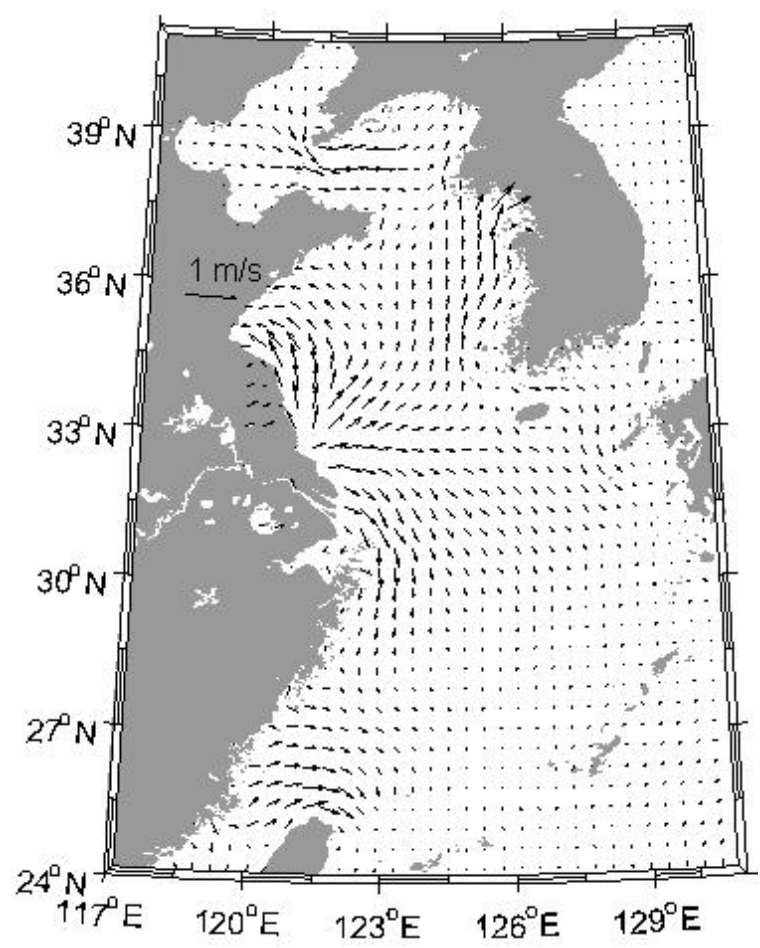

Fig. 16. The Storm surge current velocity field (at 22:00 on August 7, 2011)

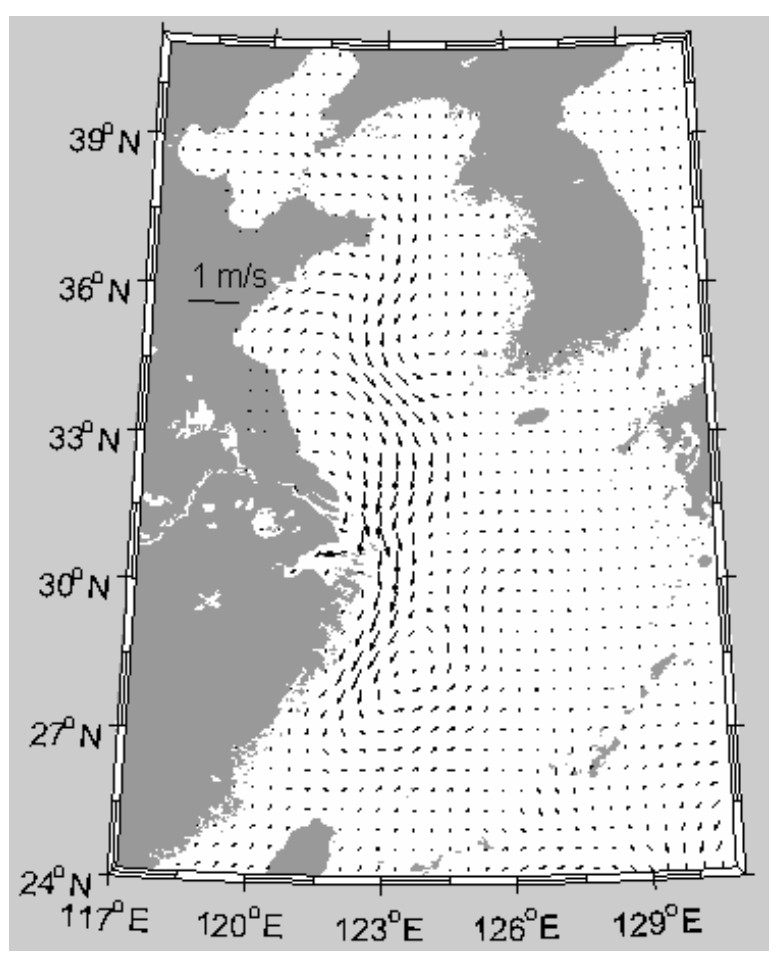

Fig. 17. The wind driven current velocity field (at 22:00 on August 7, 2011). 


\section{CONCLUSION}

Based on the SELFE model, the numerical model of the astronomical tide in the East China Sea has been established and verified. Based on this, the wind field calculated from the Fujita field model and the Miyazaki masae wind field model and the numerical model of the mid-range numerical weather forecasting center, the numerical simulation and verification of the storm surge of typhoon 1109 is carried out. Through comparison and analysis, we have confirmed the calculation model of typhoon wind field in Jiangsu coastal. This study is of engineering guidance value to the development and utilization of coastal wind energy in Jiangsu Province.

\section{ACKNOWLEDGMENT}

This study was supported by the National Nature Science Foundation Fund of China Project (51279055).WU Dean*: The corresponding author,email:wudeian@163.com

\section{REFERENCES}

[1] X. I. Wang, Q. J. Yin, and B. M. Zhang, "Research and applications of a forecasting model of typhoon surges in China seas," Advances in Water Science, vol. 2, no. 1, pp. 1-10, Jan. 1991.

[2] T. Fujita, "Pressure distribution within typhoon," Geophysical Magazine, vol. 23, no. 4, pp. 437-451, Oct. 1952.

[3] S. X. Zhu, W. Y. Sha, and P. X. Ding, "An asymmetry wind field model of typhoon near shore," Journal of East China Normal University (Natural Science), no. 3, pp. 66-71, Mar. 2002.

[4] G. J. Holland, "An analytic model of the wind and pressure profiles in hurricanes," Monthly Weather Review, vol. 108, no. 8, pp. 1212-1218, Aug. 1980.

[5] L. F. Sheng and Z. M. Wu, "A new fitting method for sea surface wind field of typhoon," Journal of Tropical Meteorology, vol. 9, no. 3, pp. 265-271, Mar. 1993

[6] Z. Z. Yang, W. Y. Sha, and S. X. Zhu, "A new nonsymmetrical model of the sea surface pressure and wind fields about typhoon," Marine Science Bulletin, vol. 24, no. 2, pp. 62-68, Jan. 2005.

[7] H. J. Zhao, Z. Y. Song, and F. M. Xu, "Numerical simulation of typhoon waves in the south china sea - A case study of typhoon chanchu," The Ocean Engineering, vol. 28, no. 3, pp. 128-134, June 2010.

[8] J. D. Loftis, "Development of a large-scale storm surge and high-resolution sub-grid inundation modelfor coastal flooding applications - A case study during 2012 hurricane sandy," Ph.D. dissertation, College of William and Mary in Virginia. 2014.

[9] S. L. Zhao, "Numerical study of storm surge in Jiangsu coastal areas," M. S. thesis, College of Harbor, Coastal and Offshore Engineering, Hohai University, Nanjing, China, 2015.

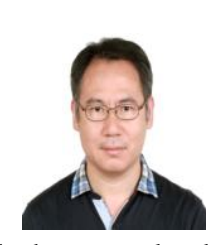

D. A. Wu was born in Xuzhou, Jiangsu, China. He received his Sc. D in physical geography, Joint training doctoral of Nanjing Normal University and Ocean Research Institute of Chinese Academy of Science Nanjing, Jiangsu, China, 2004; he received his M.S. D in physical oceanography from Ocean University, Qingdao, China, 2000. The major field of study are harbor, coastal and offshore engineering.

He made many research results. His publications are as follows: "Research on fine-grained suspended sediment motion of dumping mud in the Changjiang deepwater navigation channel based on EFDC model," Journal of Hydrodynamics, 2010, vol. 22, no. 6, pp. 760-772. "Numerical simulation of the transport and diffusion of dissolved pollutants in the Yangtze River estuary," Chinese Journal of Oceanology and Limnology, 2010. "Research on evaluation system and key technology of the wetlands evolution and degeneration in large river mouth in china," in Proc. the Chinese-Germany Joint Symposium on Hydraulic and Ocean Engineering, August 24-30,2008, Darmstadt, Germany. He is now engaged in coastal and estuarine dynamics and numerical simulation on environmental research as a researcher of Hohai University, Nanjing, Jiangsu Province in China.

Dr. Wu has been engaged in the research of the following projects recently such as, (1) "Research on the Dynamic Characteristics of Edge Wave in the Waters by Theoretical Solution and Numerical Simulation" for the National Natural Sciences Foundation of China. (2)"Research on Evaluation System and Key Technology of the Wetlands Evolution and Degeneration in Large River Mouth in China" for the Specialized Fund of Public Welfare Special Scientific Research Project Funded by China Ministry of Water Resources.

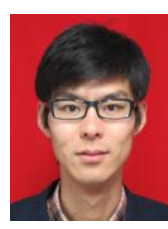

S. L. Zhao was born in Yantai, Shandong, China. Date of Birth: Aug 6, 1989. He received his M.E. harbor in coastal and offshore engineering from Hohai University in 2015; He received his B.S. in marine techniques from Hohai University. a M.S. D in engineering from Hohai University, Nanjing, Jiangsu Province of China, 2015. The major field of study are harbor, coastal and offshore engineering. $\mathrm{He}$ is active in social activities, being an outstanding leader. He had been the President of English Club, the Captain of College Basketball Team, the Recreation \& Sports Secretary and the Member of Students Association Union. Publications are as follows: "Vertical distribution of suspended sediment concentration based on parabolic mixing length of Sediment-laden flow," in Proc. the 7th Chinese-German Joint Symposium on Hydraulic and Ocean Engineering, Germany, 2014; "Nonlinear dispersion relation and wave transformation model," Journal of Waterway and Harbor, 2014, vol. 35, no. 3, pp. 203-208; "Vertical distribution of suspended sediment concentration in estuary and coast based on log-linear velocity distributionl," Journal of Hohai University (Natural Sciences). He is now engaged in civil \& environmental engineering research for the Design Institute of Water Conservancy and Hydroelectric Power of Zhejiang.

Mr. Zhao has excellent performances in his academic research. The parts of the awards are as follows: (1) The National Scholarship; (2) The First Prize (3) Scholarship ; (4) Excellent Academic Scholarship. 